Affection Deprivation Is Associated with Physical Pain and Poor Sleep Quality

Kory Floyd

University of Arizona

Author notes. Kory Floyd (Ph.D., University of Arizona, 1998) is professor of communication at the University of Arizona. The assistance of Dr. Perry Pauley is gratefully acknowledged. Address correspondence to Department of Communication, University of Arizona, PO Box 210025, Tucson AZ 85721-0025. (520) 621-8236. E-mail: koryfloyd@email.arizona.edu 


\begin{abstract}
Social bonds are necessary for human survival and affectionate communication is paramount for their formation and maintenance. Consequently, affection deprivation - the condition of receiving less affectionate communication than desired-is associated with social pain, and contemporary research indicates that social pain has substantial neurological overlap with physical pain. Thus, it was proposed that affection deprivation would be associated with the sensation of physical pain as well as with poor quality sleep. Three studies involving a total of 1,368 adults from nearly all U.S. states and several foreign countries revealed significant associations between affection deprivation, physical pain, and multiple facets of disturbed sleep.
\end{abstract}

Keywords: Affection; Pain; Sleep; Affection Exchange Theory 


\section{Affection Deprivation Is Associated with Physical Pain and Poor Sleep Quality}

For such a social species as Homo sapiens, the formation of significant social bonds is much more a necessity than a luxury. As Baumeister and Leary (1995) explained, humans have a fundamental, evolved drive to maintain close interpersonal attachments, and they thrive when this need is satisfied but suffer impairments when it is thwarted. Affection is one of the chief communication behaviors contributing to the formation (Owen, 1987), maintenance (Bell \& Healey, 1992), and quality (Floyd \& Morman, 1997, 1998, 2000a) of such relationships. For that reason, scholars and clinicians alike have long considered affection to be among the most fundamental of human needs (Floyd, 2006a; Rotter, Chance, \& Phares, 1972; Schutz, 1958, 1966). Affection supports physical health (Floyd, Pauley, \& Hesse, 2010), mental well-being (Hesse \& Floyd, 2008), and academic performance (Steward \& Lupfer, 1987), and mitigates loneliness (Downs \& Javidi, 1990) and depression (Oliver, Raftery, Reeb, \& Delaney, 1993). Although affection can be unwelcome in certain situations (Floyd \& Burgoon, 1999; Floyd \& Morman, 2000b; Floyd \& Voloudakis, 1999), it is typically associated with numerous positive outcomes.

Any given need can be met, exceeded, or unsatisfied. All humans need food, for example, yet some people eat the amount required for good health, some eat more than is required, and some eat less than is required. Conceiving of affection as a need raises the same possibilities: Whereas some people receive adequate affection and others receive an abundance, still others experience affection deprivation. Floyd (2014) introduced affection deprivation as a theoretic construct indexing a state in which individuals receive a level of affectionate expression from others that is inadequate to meet their needs. Failing to meet any fundamental human need has negative consequences; whereas inadequate food intake leads to hunger, inadequate water intake leads to thirst, and inadequate sleep leads to fatigue, Floyd explained that inadequate affection leads to social pain that manifests in the form of loneliness, depression, feelings of isolation, and impaired interpersonal attachments.

Much contemporary research indicates, however, that social pain also manifests itself in the form of physical pain. Although people commonly think of "heartache” or "hurt feelings" only metaphorically, 
brain imaging studies demonstrate that the body processes social and physical pain as similar sensory experiences. It therefore stands to reason that affection deprivation is associated with physical pain, and if it is, it may also be associated with detriments related to physical pain, such as poor quality sleep.

That affection deprivation predicts social pain is suggested clearly by affection exchange theory, whose principles are reviewed below. Following that is a review of research linking social and physical pain and establishing that states similar to affection deprivation—such as loneliness and social rejection— are associated with physical pain and sleep disturbances. Hypotheses about the relationships between affection deprivation, pain, and sleep appear subsequently.

\section{Affection Exchange Theory}

Affectionate communication is conceptualized in affection exchange theory (AET: Floyd, 2006a) as an adaptive behavior that contributes to humans' superordinate motivations for viability (survival) and fertility (procreation). AET adopts a neo-Darwinian perspective by proposing that behavioral tendencies favorable to survival and procreation are reinforced through natural and sexual selection. These include social behaviors that contribute to the formation, maintenance, and stability of personal relationships. AET concurs with Baumeister and Leary’s (1995) need-to-belong hypothesis that humans have an innate (i.e., unlearned) need to form and nurture close personal relationships, and AET offers that affectionate communication is one of the principal behaviors responsible for satisfying that need. Multiple experimental and correlational experiments have confirmed associations between affectionate communication and relational satisfaction (Floyd, 2002; Morman \& Floyd, 1999), as well as health benefits, such as the management of stress hormones (Floyd, 2006b; Floyd \& Riforgiate, 2008); resting heart rate (Floyd, Mikkelson, Tafoya et al., 2007b); resting blood pressure (Floyd, Hesse, \& Haynes, 2007); blood lipids (Floyd et al., 2009; Floyd, Mikkelson, Hesse, \& Pauley, 2007); and recovery from elevated distress (Floyd, Mikkelson, Tafoya et al., 2007a; Floyd, Pauley, \& Hesse, 2010).

In multiple ways, therefore, affectionate behavior contributes to evolutionary fitness, making it logical to presume that affection deprivation—conceptualized as less affectionate communication than one desires—is detrimental to fitness. In an initial test of that hypothesis, Floyd (2014) surveyed 509 
adults, who came from all 50 U.S. states, the District of Columbia, Puerto Rico, and 16 foreign countries. He found significant associations with affection deprivation across five broad domains: general wellbeing, social well-being, mental health, physical health, and interpersonal attachment. Specifically, affection deprivation was positively related to loneliness, depression, stress, fearful avoidant attachment, preoccupied attachment, and alexithymia (a personality trait characterized by the inability to understand emotions and decode emotion displays). It was also related to the number of diagnosed mood/anxiety disorders and the number of diagnosed secondary (i.e., acquired) immune disorders. Conversely, affection deprivation was negatively associated with happiness, general health, social support, secure attachment, and satisfaction in one’s primary relationship. These findings are in concert with a robust literature demonstrating health and relational deficits associated with similar states of deprivation, such as loneliness (Cacioppo et al., 2002), ostracism (Hitlan, Cliffton, \& DeSoto, 2009), stigmatization (Smart Richman \& Leary, 2009), rejection (Baumeister, Brewer, Tice, \& Twenge, 2007), social exclusion (Eisenberger, Lieberman, \& Williams, 2003), and bullying (Hansen et al., 2006). Considered collectively, these studies confirm that conditions reflecting inadequate or poor-quality personal relationships are associated with detriments to physical health, mental and emotional health, and social wellness, as both AET and the need-to-belong hypothesis would predict.

\section{Affection Deprivation and Social Pain}

Scholars (e.g., Masten, Morelli, \& Eisenberger, 2011) use the term social pain to describe the aversive state caused when an individual's attempts to maintain close, satisfying personal relationships are thwarted. Experimental studies show that social pain—colloquially referred to as "hurt feelings"—is induced when individuals feel excluded from interpersonal interaction (MacDonald \& Jensen-Campbell, 2011), even when rejected online by complete strangers (Vangelisti, Pennebaker, Brody, \& Guinn, 2014). That failing to maintain adequate social bonds would cause distress is in line with the proposition of both AET and the need-to-belong hypothesis that positive, meaningful social relationships are paramount for the health and well-being of humans. 
Thornhill and Thornhill (1989) took a similar evolutionary approach in their pain theory by positing that the functions of emotional or social pain are analogous to that of physical pain: to focus attention on threatening or harmful events and to promote corrective and preventative actions. For instance, the physical pain of touching a hot stove typically prompts immediate attention and alarm, the swift corrective action of removing one's hand from the stove, and extra care to prevent the event from reoccurring. Likewise, social pain caused by isolation, ostracism, or loneliness focuses attention on a person's solitary status and can prompt corrective action in the form of repairing damaged relationships or seeking new ones. It may also produce a level of resolve to avoid such isolation in the future.

Alongside rejection, isolation, and ostracism, affection deprivation is a similarly aversive state, insofar as it reflects the lack of adequate affectionate communication. AET hypothesizes that adequate affection is necessary for well-being, and a voluminous literature confirms the mental, physical, and relational benefits of affectionate communication (for recent reviews, see Floyd, in press; Floyd, Hesse, \& Generous, in press). It is therefore logical to presume that being deprived of receiving a sufficient level of affection from others is associated with experiences of social pain, and previous research confirms the relationship of affection deprivation to various manifestations of social pain, such as anxiety, insecure attachment, loneliness, and depression (Floyd, 2014).

Despite a tendency to think of social or emotional pain as a psychological experience distinct from that of physical pain, research indicates substantial sensory overlap between them. Therefore, although social pain is aversive on its own, it may also manifest in the body in the form of physical pain sensations, making physical pain a potential correlate of affection deprivation.

\section{Connections to Physical Pain}

Nearly four decades ago, Panksepp and colleagues advanced the argument that social and physical pain are similar sensory experiences (Herman \& Panksepp, 1978; Panksepp, Herman, Conner, Bishop, \& Scott, 1978; Panksepp, Vilberg, Bean, Coy, \& Kastin, 1978). They argued that as natural selection prepared animals for increased social interaction, instead of creating novel systems to react to 
socially distressing events (such as exclusion or rejection), it piggybacked those responses onto existing systems already prepared to respond to physical pain.

Compelling evidence in support of Panksepp’s proposition comes from neuroimaging studies showing that social and physical pain activate similar neural structures. Chief among these structures is the anterior cingulate cortex (Bush, Luu, \& Posner, 2000; Kimbrell et al., 1999; Nelson \& Panksepp, 1998), specifically the dorsal subdivision (dACC; Eisenberger \& Lieberman, 2004), which is active in both the affective and attentional concomitants of pain sensation, according to meta-analyses of research using positron emission tomography (PET) and functional magnetic resonance imaging (fMRI; Peyron, Laurent, \& García-Larrea, 2000). As Eisenberger et al. (2003) reported, the anterior cingulate cortex is also activated by experiences of social rejection. Participants in their study were scanned by fMRI while playing a virtual ball-tossing game (“Cyberball”), in which they were ultimately excluded by their coplayers. As in studies of physical pain, Eisenberger and colleagues found that the anterior cingulate cortex was more active when participants were socially excluded than when they were included, and that activation correlated positively with self-reports of distress.

Other neurological structures show similar overlap between physical and social pain. Kross, Berman, Mischel, Smith, and Wager (2011) found that experience of social rejection activated the secondary somatosensory cortex and dorsal posterior insula, both of which are normally associated with (and highly diagnostic of) the sensory experience of physical pain. The periaqueductal gray, located in the midbrain, has also been linked to both physical and social pain (An, Bandler, Öngür, \& Price, 1998; Floyd, Price, Ferry, Keay, \& Bandler, 2000).

The discovery that the brain processes physical and social pain similarly helps to explain why experiences of social deprivation show reliable associations with physical pain. Specifically, physical pain is positively associated with loneliness (Cacioppo \& Patrick, 2008; Jaremka et al., 2013), social exclusion (MacDonald \& Leary, 2005; but see DeWall \& Baumeister, 2006), ostracism (Williams, 2007), and loss of an important social relationship (Panksepp, 2003). Common to these conditions is the inability to meet one’s need for meaningful social bonds. As affection deprivation also represents an impairment to 
fundamental social needs, it is hypothesized that affection deprivation is directly associated with physical pain (H1).

\section{Connections to Sleep Quality}

The social pain resulting from the lack of meaningful connection can manifest itself in ways other than physical pain. One candidate is the quality of sleep people experience. Kurina et al. (2011) offered an evolutionary argument for why social deprivation might impair sleep:

Humans must have relied on a safe social surround to survive and thrive. The absence of a secure social environment results in perceptions of social isolation that, in turn, have been shown to increase vigilance for threat and to heighten feelings of vulnerability. This heightened vigilance may be manifested during the sleep period in greater restlessness or more fragmented sleep. (p. 1519)

In support of their argument, Kurina and colleagues found a positive relationship ( $\beta=.06$ ) between loneliness and sleep fragmentation, an index of restlessness. They also found that loneliness predicted lower sleep duration ( $\beta=-.13$ ), although previous studies of loneliness had generally failed to find an association with sleep duration (e.g., Mahon, 1994). Steptoe, Owen, Kunz-Ebrecht, and Brydon (2004) likewise found a positive association $(\beta=.15)$ between loneliness and sleep problems, a relationship that was independent of age, sex, marital status, and employment status. Other investigations have also documented that poor sleep quality is associated with bullying (Niedhammer, 2009) and negative mood (Thomsen, Mehlsen, Christensen, \& Zachariae, 2003).

The argument offered by Kurina et al. reflects the presumption of AET and the need-to-belong hypothesis that strong social relationships are paramount to human survival and wellness. Failure to meet that need results in heightened distress (in the form of vulnerability and increased vigilance) that disturbs sleep, according to Kurina and colleagues. Insofar as affection deprivation also reflects the failure to maintain adequately close personal relationships, it is hypothesized that affection deprivation is inversely associated with sleep quality (H2). 
Three studies are reported here to test the hypothesized relationships between affection deprivation, pain, and sleep quality. The first study tests H1 only, whereas the second and third studies test both predictions.

\section{Study One}

The purpose of the first study is to determine the validity of H1, which predicted a significant linear association between affection deprivation and pain.

\section{Participants}

Participants $(N=572)$ were 314 men and 258 women. Most $(68.4 \%)$ self-identified as White/Caucasian, whereas 17.8\% were Asian/Pacific Islander, 8.4\% were Black/African American, 5.2\% were Hispanic/Latino(a), 1.9\% were Native American, and 1.6\% claimed other ethnic origins. ${ }^{1}$ Ages ranged from 18 to 72 years $(M=33.49$ years, $S D=11.41)$. Participants came from every U.S. state except North and South Dakota, and also from the District of Columbia and nine foreign countries (Angola, Argentina, Bulgaria, Canada, Egypt, India, the Netherlands, Romania, and the United Arab Emirates).

\section{Procedure}

All procedures were approved by the university’s institutional review board. Participants were recruited via the Amazon.com Web Services crowdsourcing marketplace Mechanical Turk (MTurk). MTurk is an online venue where workers—called providers_-perform functions provided by companies or organizations — called requesters — in exchange for payment in the form of money or Amazon.com gift cards. In the case of the present study, a work assignment—called a hit on MTurk—was created in which providers were asked to take part in a survey about social relationships. Those who elected to participate clicked on a link to an online questionnaire. At the conclusion of the questionnaire, providers received a code to enter on the MTurk site to verify their completion of the task. Participation was limited to providers 18 years of age or older. Providers received \$2US in exchange for filling out the questionnaire, which took the average provider 11 minutes, 55 seconds to complete. A recent study found that samples recruited on MTurk for academic research are often more representative of the U.S. population than are 
in-person convenience samples (Berinksy, Huber, \& Lenz, 2012; see also Paolacci, Chandler, \& Opeirotis, 2010).

\section{Measures}

Affection deprivation was measured with a modified version of the scale developed by Floyd (2014). ${ }^{2}$ Items address participants' dissatisfaction with the amount of affection they receive from other people (e.g., "I don’t get enough affection from others,” "I often wish I got more affection in my life”). The scale employed a nine-point Likert-type scale wherein higher scores reflect a greater level of affection deprivation $(\alpha=.92)$.

Physical pain was measured using the pain subscale of the RAND Short Form Health Survey (SF-36; see Hays, Sherbourne, \& Mazel, 1995). The items on the pain subscale were "How much bodily pain have you had during the past 4 weeks?” and “During the past 4 weeks, how much did pain interfere with your normal work (including both work outside the home and housework)?” with a modified ninepoint scale in which higher scores indicate greater pain $(\alpha=.93)$. The SF-36 has been extensively validated as a primary health care assessment (Brazier et al., 1992), and as Kurina et al. (2013) pointed out, the pain subscale of the SF-36 is beneficial compared to alternate measures because it is not tied to any specific pathology.

\section{Results}

Descriptive analyses. Observed scores for affection deprivation ranged from 1 to 9, with a mean of $4.72(S D=2.01)$. Men's average affection deprivation score $(M=4.59, S D=1.91)$ did not differ significantly from women's $(M=4.84, S D=2.14), t(570)=-1.48, p=.14$ (two tailed). Affection deprivation evidenced a significant inverse association with age, $r(570)=-.15, p<.001$ (two tailed). With respect to ethnicity, those of Asian/Pacific Islander descent reported greater affection deprivation ( $M$ $=5.24, S D=1.46)$ than those who were not of Asian/Pacific Islander descent $(M=4.60, S D=2.10), t$ $(578)=2.95, p<.001$; moreover, Caucasians reported less affection deprivation $(M=4.60, S D=2.09)$ 
than non-Caucasians $(M=4.97, S D=1.81), t(578)=-2.08, p=.04$ (both probabilities are two tailed). No other ethnic comparisons were significant.

Observed scores for pain ranged from 1 to 9 , with a mean of $2.72(S D=2.60)$, suggesting that the average participant did not experience intense physical pain. Men's average score for pain $(M=2.47, S D$ $=2.41$ ) was significantly lower than women's $(M=3.03, S D=2.78), t(566)=-2.59, p=.01$ (two tailed). Pain manifested a moderate association with age, $r(570)=.12, p=.005$ (two tailed). There were no effects of ethnicity on pain scores.

Hypothesis 1. The first hypothesis predicted a significant association between affection deprivation and physical pain. As shown in Table 1, affection deprivation had a significant bivariate correlation with physical pain intensity. Because pain was associated with both age and sex, it was analyzed in a hierarchical regression in which age and sex (dummy coded as male $=0$ ) were entered in the first step and affection deprivation was entered in the second step. Collinearity diagnostics were unremarkable (tolerance and VIF values were all near 1). The regression produced a significant omnibus model, and after controlling for the effects of age and sex, affection deprivation was significantly associated with physical pain, $\beta=.12, p=.004$. Full regression results appear in Table 1 . The first hypothesis is supported.

\section{Discussion}

The first study supported the preliminary hypothesis that affection deprivation is associated with physical pain. Although the association (net of the effects of age and sex) was modest in magnitude, it was in line with the result of studies focused on other forms of social exclusion (for instance, Jaremka et al. (2013) identified an association between pain and loneliness of $\beta=.16$ ). Whereas affection deprivation shows a significant association with pain, this result suggests the need for replication and caution against exaggerating its magnitude.

\section{Study Two}


The second study was designed to replicate the test of $\mathrm{H} 1$ and also to test $\mathrm{H} 2$, which predicted a significant inverse association between affection deprivation and sleep quality.

\section{Participants}

Participants $(N=399)$ were 212 men, 183 women, and four who declined to report their biological sex. Most (69.9\%) self-identified as White/Caucasian, whereas 17.5\% were Asian/Pacific Islander, 7.3\% were Black/African American, 6.5\% were Hispanic/Latino(a), 2.0\% were Native American, and $0.8 \%$ claimed other ethnic origins. Ages ranged from 18 to 74 years $(M=33.86$ years, $S D$ = 11.14). Participants came from 42 U.S. states, the District of Columbia, Puerto Rico, and six foreign countries (Canada, India, Ireland, Mexico, South Korea, and Sweden).

\section{Procedure}

Procedures were identical to those of Study One except that the online questionnaire on MTurk included a sleep quality measure. Participants again received \$2US in exchange for their involvement.

\section{Measures}

Affection deprivation was again measured with a modified version of the scale developed by Floyd (2014; $\alpha=$.94). Physical pain was again measured using the pain subscale of the RAND SF-36 (Hays et al., 1995; $\alpha=.93$ ).

Sleep disturbance was measured with the Pittsburgh Sleep Quality Index (PSQI; Buysse, Reynolds, Monk, Berman, \& Kupfer, 1989). The instrument contains 19 items that generate seven component scores: 1) sleep quality; 2) sleep latency; 3) sleep duration; 4) habitual sleep efficiency; 5) sleep disturbances; 6) use of sleeping medications; and, 7) daytime dysfunction. Total possible scores ranged from 0 to 21, with higher scores indicating poorer sleep quality (i.e., more problematic sleep; $\alpha=$ .68). Previous research has extensively validated the PSQI as a sleep quality assessment (Backhaus, Junghanns, Broocks, Riemann, \& Hohagen, 2002; Beck, Schwartz, Towsley, Dudley, \& Barsevick, 2004; Carpenter \& Andrykowski, 1998).

\section{Results}


Descriptive analyses. Observed scores for affection deprivation ranged from 1 to 9 , with a mean of $4.67(S D=2.05)$. Men's average affection deprivation score $(M=4.66, S D=1.96)$ did not differ significantly from women's $(M=4.68, S D=2.16), t(393)=-.12, p=.90$ (two tailed). Affection deprivation was unrelated to age, $r(395)=.01, p=.82$ (two tailed). As in Study One, those of Asian/Pacific Islander descent reported greater affection deprivation $(M=5.19, S D=1.65)$ than those who were not of Asian/Pacific Islander descent $(M=4.56, S D=2.11), t(397)=2.34, p=.02$; moreover, Caucasians reported less affection deprivation $(M=4.45, S D=2.07)$ than non-Caucasians $(M=5.17, S D$ $=1.92), t(397)=-3.27, p=.001$ (both probabilities are two tailed). No other ethnic comparisons were significant.

Observed scores for pain ranged from 1 to 9 , with a mean of $2.78(S D=2.61)$, suggesting that the average participant did not experience intense physical pain. Men's average score for pain $(M=2.27, S D$ $=2.20$ ) was significantly lower than women's $(M=3.34, S D=2.92), t(391)=-4.10, p<.001$ (two tailed). Pain manifested a moderate association with age, $r(393)=.19, p<.001$ (two tailed). There were no effects of ethnicity on pain scores. Finally, observed scores for sleep disturbance ranged from 0 to 17 , with a mean of $6.26(S D=3.33)$. Women reported significantly greater sleep disturbance $(M=6.77, S D=$ 3.54) than did men $(M=5.82, S D=3.06), t(393)=-2.86, p=.004$ (two tailed). Sleep disturbance was uncorrelated with age, $r(395)=.10, p=.05$ (two tailed), and there were no effects of ethnicity.

Hypothesis 1. The first hypothesis predicted a significant association between affection deprivation and physical pain. As shown in Table 2, affection deprivation had a significant bivariate correlation with physical pain intensity. Because pain was associated with both age and sex, it was analyzed in a hierarchical regression in which age and sex (dummy coded as male $=0$ ) were entered in the first step and affection deprivation was entered in the second step. Collinearity diagnostics were unremarkable. The regression produced a significant omnibus model, and after controlling for the effects of age and sex, affection deprivation was significantly associated with physical pain, $\beta=.15, p=.002$. Full regression results appear in Table 2. The first hypothesis is again supported. 
Hypothesis 2. The second hypothesis predicted that affection deprivation is associated with poor sleep quality. As Table 3 shows, affection deprivation had a significant bivariate correlation with lowquality sleep (the correlation coefficient with sleep disturbance is positive because higher scores on the sleep quality index correspond to lower sleep quality). Because sleep quality scores differed by sex, it was examined in a hierarchical regression in which sex was entered in the first step and affection deprivation was entered in the second step. Collinearity diagnostics were unremarkable. The regression produced a significant omnibus model, and after controlling for the effect of sex, affection deprivation was significantly associated with sleep disturbance, $\beta=.29, p<.001$. Full regression results appear in Table 3. The second hypothesis is supported.

For exploratory purposes, bivariate correlations were calculated between affection deprivation and the seven components of sleep disturbance assessed by the sleep quality index. To varying degrees, affection deprivation was significantly and directly correlated with each component of disturbed sleep, except for the use of sleeping medications. Correlation coefficients appear in Table 4.

\section{Discussion}

As in the first study, affection deprivation was associated with pain (net of the effects of age and sex), and to a slightly stronger degree ( $\beta \mathrm{s}=.12$ in Study One and .15 in Study Two). Affection deprivation also showed a moderate relationship with overall sleep quality, despite a modest inter-item reliability for the PSQI, indicating that affection-deprived individuals experience poorer quality sleep than their non-deprived counterparts. This result supports H2. Importantly, zero-order correlations show that affection deprivation is related most strongly to sleep disturbances, sleep quality, and daytime dysfunction, but does not predict the use of sleeping medications.

Although the significant effect of sex on sleep quality was controlled in the test of H2, one limitation of Study Two is that other potential moderators of sleep quality—such as exercise habits, tobacco and alcohol use, current illness, and body mass-were not accounted for. Each of these factors has the potential to affect sleep quality independently of affection deprivation, so accounting for their 
possible moderating effects would strengthen confidence in the findings. Study Three was conducted to remedy this limitation.

\section{Study Three}

The third study was designed to replicate the tests of $\mathrm{H} 1$ and $\mathrm{H} 2$ while controlling for the potential moderating effects on sleep quality of exercise, tobacco use, alcohol use, current illness, and body mass.

\section{Participants}

Participants $(N=397)$ were 232 men, 160 women, and five who declined to report their biological sex. Most (76.8\%) self-identified as White/Caucasian, whereas 11.3\% were Asian/Pacific Islander, 9.3\% were Hispanic/Latino(a), 5.8\% were Black/African American, 2.3\% were Native American, and $0.5 \%$ claimed other ethnic origins. Ages ranged from 18 to 68 years $(M=32.66$ years, $S D$ $=10.24)$. Participants came from 44 U.S. states, the District of Columbia, and three foreign countries (Canada, Trinidad and Tobago, and the United Kingdom).

\section{Procedure}

Procedures were identical to those of Study Two except for the addition of measures of potential sleep quality moderators. Participants again received \$2US in exchange for their involvement.

\section{Measures}

Affection deprivation was again measured with a modified version of the scale developed by Floyd (2014; $\alpha=.95)$. Physical pain was again measured using the pain subscale of the RAND SF-36 (Hays et al., 1995; $\alpha=.91$ ). Sleep disturbance was again measured with the PSQI (Buysse et al., 1989; $\alpha$ =.66). Exercise was measured by asking participants to report how many hours they have spend In the past week jogging, walking, swimming, riding a bicycle, or doing other forms of exercise. Tobacco and alcohol use were each measured by asking participants to report on how many days (0-7) in the past week they have used tobacco products or consumed alcohol. Body mass index was calculated based on participants' reports of their height and weight, using the Centers for Disease Control and Prevention 
(CDC) formula. ${ }^{3}$ Current illness was measured by asking participants whether they currently had a cold, flu, or other illness.

\section{Results}

Descriptive analyses. Observed scores for affection deprivation ranged from 1 to 9, with a mean of $4.47(S D=2.05)$. As in the first two studies, men's average affection deprivation score $(M=4.54, S D$ $=2.01$ ) did not differ significantly from women's $(M=4.38, S D=2.11), t(390)=.79, p=.43$ (two tailed). Affection deprivation was uncorrelated with age, $r(395)=.01, p=.78$ (two tailed). Unlike in the first two studies, there were no differences among ethnic groups.

Observed scores for pain ranged from 1 to 9, with a mean of $2.69(S D=2.05)$. As in the previous two studies, men's average score for pain $(M=2.41, S D=1.80)$ was significantly lower than women's $(M=3.11, S D=2.31), t(390)=-3.36, p=.001$ (two tailed). Pain manifested a moderate association with age, $r$ (395) $=.14, p=.006$ (two tailed). There were no effects of ethnicity. Finally, observed scores for sleep disturbance ranged from 5 to 21, with a mean of $11.29(S D=3.70)$. Unlike in Study Two, women’s sleep disturbance $(M=11.75, S D=4.11)$ did not differ significantly from men's $(M=11.03, S D=3.30)$, $t(390)=-1.92, p=.056$ (two tailed). Sleep disturbance was correlated with age, $r(395)=.11, p=.03$ (two tailed), and there were no effects of ethnicity.

Regarding the potential moderators of sleep quality, only BMI showed a correlation with sleep quality $r(395)=.12, p=.03$. Sleep quality was unrelated to exercise, tobacco use, and alcohol use, and there was no significant difference in sleep quality between those who were and were not ill at the time of the study.

Hypothesis 1. The first hypothesis predicted a significant association between affection deprivation and physical pain. As shown in Table 5, affection deprivation had a significant bivariate correlation with physical pain intensity. Because pain was associated with both age and sex, it was analyzed in a hierarchical regression in which age and sex (dummy coded as male $=0$ ) were entered in the first step and affection deprivation was entered in the second step. The regression produced a significant omnibus model, and after controlling for the effects of age and sex, affection deprivation was 
significantly associated with physical pain, $\beta=.15, p<.001$. Full regression results appear in Table 5 . The first hypothesis is again supported.

Hypothesis 2. The second hypothesis predicted that affection deprivation is associated with sleep disturbance. As Table 6 shows, affection deprivation had a significant bivariate correlation with lowquality sleep. Because sleep disturbance scores differed by sex and were related to BMI, it was examined in a hierarchical regression in which sex and BMI were entered in the first step and affection deprivation was entered in the second step. The regression produced a significant omnibus model, and after controlling for the effect of sex and BMI, affection deprivation was significantly associated with sleep disturbance, $\beta=.26, p<.001$. Full regression results appear in Table 6 . The second hypothesis is again supported.

For exploratory purposes, bivariate correlations were calculated between affection deprivation and the seven components of sleep disturbance assessed by the sleep quality index. Affection deprivation was significantly correlated with four of the components of disturbed sleep; it was uncorrelated with sleep duration, efficiency, and the use of sleeping medications. Correlation coefficients appear in Table 4.

\section{Discussion}

As in the first two studies, affection deprivation was again associated with pain, manifesting the same magnitude of relationship in Study Two and Study Three $(\beta s=.15)$. Although the association is not particularly strong, it is consistent across all three samples and, as indicated earlier, it is consistent with the magnitude of associations found in loneliness research. We can therefore conclude that affection deprivation covaries at least to a modest degree with the experience of physical pain in adults. H1 is therefore supported across all three studies.

Affection deprivation again showed a moderate relationship with overall sleep quality, with the magnitude of association in Study Three $(\beta=.26)$ being similar to that of Study Two $(\beta=.29)$. H2 is therefore supported across both studies. Zero-order correlations again show that affection deprivation is related to sleep quality, sleep disturbance, and daytime dysfunction, as well as sleep latency. 
Among the potential moderators of sleep quality, only body mass index showed a correlation with sleep quality, which is consistent with research on sleep and obesity (see Gupta, Mueller, Chan, \& Meininger, 2002; Javaheri, Storfer-Isser, Rosen, \& Redline, 2008). BMI was therefore controlled in the analysis testing a relationship between sleep quality and affection deprivation. Sleep quality showed no significant associations with exercise, tobacco use, and alcohol use, or current illness. Insofar as these factors have been shown in previous studies to affect sleep (e.g., King, Oman, Brassington, Bliwise, \& Haskell, 1997; Patten, Choi, Gillin, \&Pierce, 2000; Singleton \& Wolfson, 2009), their failure to moderate sleep quality in the current study may be a function of measurement, warranting replication in a future study with more psychometrically sound instruments.

\section{General Discussion}

A robust literature has identified a broad range of mental and physical health benefits associated with expressing and receiving affection. Some forms of affectionate communication, such as kissing (Floyd et al., 2009) and handholding (Grewen, Anderson, Girdler, \& Light, 2003), have even been shown to improve specific health parameters. Besides demonstrating that the exchange of affection is beneficial, this research—along with affection exchange theory and the need-to-belong hypothesis—also implies that the absence of adequate affection may be detrimental to well-being and quality of life. In line with that argument, two parameters of wellness—physical pain and sleep quality — were shown in the present studies to have reliable associations with the experience of affection deprivation.

These findings join those of Floyd (2014), who found that affection deprivation is associated with poorer physical health (in the form of diagnosed secondary immune disorders) as well as mental and social health (e.g., depression, insecure attachment). Considered collectively, these two projects advance the concept of affection deprivation as a detriment to wellness across a range of life domains. Whereas multiple previous studies have articulated associations between communication behavior and emotional well-being (such as satisfaction or happiness; see, e.g., Litzinger \& Gordon, 2005; Pettit, Goris, \& Vaught, 1997), the present studies are among the first to link communication behavior to concrete health impairments such as pain and sleep disturbances. 
The implied causal pathway to physical pain articulated in the present studies is relatively straightforward: Affection deprivation leads to experiences of social pain, which share significantly overlapping neural pathways with physical pain. Regarding the mechanism behind the association of affection deprivation and sleep quality, however, various options are possible. Kurina et al. (2011) articulated the broad evolutionary argument that impaired social relationships (such as might be reflected by affection deprivation) heighten insecurity and increase vigilance, leading to poorer sleep. Steptoe et al. (2004) raised another possibility: Social deprivation stimulates activation of neuroendocrine, immune, and autonomic responses (such as waking levels of the steroid hormone cortisol, given that sleep debt can disturb the hypothalamic-pituitary-adrenal rhythm; Spiegel, Leproult, \& Van Cauter, 1999) that could interfere with sleep quality.

A more straightforward potential causal pathway is that affection deprivation leads to physical pain, which impairs sleep quality. The current studies have established an association between affection deprivation and pain, and pain has been shown empirically to inhibit sleep quality (e.g., Menefee et al., 2000). To determine the validity of this pathway, post-hoc analyses examined the potential mediating effect of pain on the affection deprivation-sleep quality relationship. The mediation analysis used the combined data from the second and third studies.

A potential mediating effect of pain on the relationship between affection deprivation and sleep quality was tested via the structural equation modeling (SEM) approach for testing mediation effects (Shrout \& Bolger, 2002). A path analysis was analyzed using AMOS 22.0 for Windows, using 10,000 bootstrapped samples and a bias-corrected 95\% confidence interval (CI). The analysis produced a justidentified model with zero degrees of freedom, yielding $\chi^{2}=0$. Affection deprivation was significantly related to pain, $b=.136$, and to sleep quality, $b=.331$, and pain was related to sleep quality, $b=.556$ (all $p$ 's $<.001)$. The indirect effect of affection deprivation on sleep disturbance-including pain as the mediator—was also significant, $b=.075$ (95\% CI: .032 to .129), indicating that pain mediates the relationship between affection deprivation and sleep quality, albeit to a modest degree. 
The result of the mediation analysis supports the conclusion that physical pain is one mechanism responsible for the association between affection deprivation and sleep quality, but it is likely not the only one. Future research can shed additional light on the nature of the relationship by examining, for instance, waking cortisol or other endocrine or immune stress markers, and/or differences in personal care and health behaviors that may affect sleep quality, in line with the speculation offered by Steptoe et al. (2004). It may also be useful to identify chronotypes—-that is, people's individual variants in preferred timing of sleep and activity (see Wittmann, Dinich, Merrow, \& Roenneberg, 2006)—for their potential associations with affection deprivation and/or sleep quality.

The present studies benefited from the inclusion of samples that were both geographically and demographically diverse. As others (e.g., Berinksy et al., 2012) have noted, the use of Amazon.com’s crowdsourcing tool makes such broad and diverse sampling practical for empirical research, increasing the external validity of the results compared to those produced from convenience samples of communication undergraduates. Of course, the samples were necessarily limited to those with access to computers and internet service, as well as the ability to read and write English, so although they reflected considerable diversity, they cannot be considered random samples.

Although these studies identified significant relationships between affection deprivation, pain, and sleep quality, future research can improve on certain limitations. With respect to potential moderators of sleep quality, studies would benefit from using more established, psychometrically sound assessments of exercise, tobacco use, and alcohol use, and should also assess caffeine consumption. Even though exercise, tobacco use, and alcohol use showed nonsignificant associations with sleep quality in Study Three, the probability remains that these activities do, in fact, influence sleep quality and should therefore be controlled when assessing its relationship to affection deprivation. In that vein, future research may also benefit from the use of a different pain measure, one that assesses multiple aspects of physical pain (such as location, duration, intensity). Moreover, although the modest inter-item reliabilities of the Pittsburgh Sleep Quality Index did not prevent significant relationships from emerging, suboptimal 
reliability does attenuate statistical power, suggesting that a measure with better internal reliability might yield associations of even greater magnitude.

Similar to Floyd's (2014) study of affection deprivation, the present studies were cross-sectional and therefore cannot support any causal inferences. Affection exchange theory suggests that creating affection deprivation would lead to deficits in wellness and impede optimal functioning. It is also plausible that the experiences of physical pain or poor quality sleep could also inhibit affection exchange with others. Indeed, both causal pathways may be accurate: Affection deprivation may lead to pain and sleep problems, which may lead to further affection deprivation. Identifying the relative variance accounted for by each pathway is a task for future, experimental studies.

Given the significant associations between affection deprivation, pain, and sleep quality, however, another potentially useful task for future research is to determine whether psychological or behavioral interventions aimed at reducing affection deprivation can yield improvements in pain or sleep. As noted above, some previous experiments (Floyd et al., 2009; Grewen et al., 2003) have effected improved health parameters via behavioral interventions that increased affectionate contact. If a similar intervention can produce even a modest reduction in physical pain or increase in sleep quality, it would have applied benefit for those who suffer chronically from one or both of those conditions.

In summary, meaningful social relationships are a requirement for the human species, and affectionate communication is one of the principal behaviors contributing to their formation and maintenance. Like deprivations in food, water, or other fundamental needs, affection deprivation is associated with multiple significant impairments in functioning. Among these are the existence of physical pain (a product of the social pain produced by affection deprivation) and the lack of adequate high quality restorative sleep. 


\section{References}

An, X., Bandler, R., Öngür, D., \& Price, J. L. (1998). Prefrontal cortical projections to longitudinal columns in the midbrain periaqueductal gray in macaque monkeys. Journal of Comparative Neurology, 401, 455-479. doi: 10.1002/(SICI)1096-9861(19981130)401:4<455::AID-

\section{CNE3>3.3.CO;2-Y}

Backhaus, J., Junghanns, K., Broocks, A., Riemann, D, \& Hohagen, F. (2002). Test-retest reliability and validity of the Pittsburgh Sleep Quality Index in primary insomnia. Journal of Psychosomatic Research, 53, 737-740. doi: 10.1016/S0022-3999(02)00330-6

Baumeister, R. F., Brewer, L. E., Tice, D. M., \& Twenge, J. M. (2007). Thwarting the need to belong: Understanding the interpersonal and inner effects of social exclusion. Social and Personality Psychology Compass, 1, 506-520. doi: 10.1111/j.1751-9004.2007.00020.x

Baumeister, R. F., \& Leary, M. R. (1995). The need to belong: Desire for interpersonal attachments as fundamental human motivation. Psychological Bulletin, 117, 497-529. doi: 10.1037/00332909.117.3.497

Beck, S. L., Schwartz, A. L., Towsley, G., Dudley, W., \& Barsevick, A. (2004). Psychometric evaluation of the Pittsburgh sleep quality index in cancer patients. Journal of Pain and Symptom Management, 27, 140-148. doi: 10.1016/j.painsymman.2003.12.002

Bell, R. A., \& Healey, J. G. (1992). Idiomatic communication and interpersonal solidarity in friends’ relational cultures. Human Communication Research, 18, 307-335. doi: 10.1111/14682958.1992.tb00555.x

Berinsky, A. J., Huber, G. A., \& Lenz, G. S. (2012). Evaluating online labor markets for experimental research: Amazon.com’s Mechanical Turk. Political Analysis, 20, 351-368. doi: 10.1093/pan/mpr057

Brazier, J. E., Harper, R., Jones, N. M., O’Cathain, A., Thomas, K. J., Usherwood, T., \& Westlake, L. (1992). Validating the SF-36 health survey questionnaire: New outcome measure for primary care. British Medical Journal, 305, 160-164. doi: 10.1136/bmj.305.6846.160 
Bush, G., Luu, P., \& Posner, M. I. (2000). Cognitive and emotional influence in anterior cingulate cortex. Trends in Cognitive Sciences, 4, 215-222. doi: 10.1016/S1364-6613(00)01483-2

Buysse, D. J., Reynolds, C. F., Monk, T. H., Berman, S. R., \& Kupfer, D. J. (1989). The Pittsburgh Sleep Quality Index: A new instrument for psychiatric practice and research. Psychiatry Research, 28, 193-213. doi: 10.1016/0165-1781(89)90047-4

Cacioppo, J. T., Hawkley, L. C., Berntson, G. G., Ernst, J. M., Gibbs, A. C., Stickgold, R., \& Hobson, J. A. (2002). Do lonely days invade the nights? Potential social modulation of sleep efficiency. Psychological Science, 13, 384-387. doi: 10.1111/1467-9280.00469

Cacioppo, J. T., Hawkley, L. C., Crawford, E., Ernst, J. M., Burleson, M. H., Kowalewski, R. B., ...Berntson, G. G. (2002). Loneliness and health: Potential mechanisms. Psychosomatic Medicine, 64, 407-417. doi: 10.1097/00006842-200205000-00005

Cacioppo, J. T., \& Patrick, W. (2008). Loneliness: Human nature and the need for social connection. New York, NY: W. W. Norton.

Carpenter, J. S., \& Andrykowski, M. A. (1998). Psychometric evaluation of the Pittsburgh sleep quality index. Journal of Psychosomatic Research, 45, 5-13. doi: 10.1016/S0022-3999(97)00298-5

DeWall, C. N., \& Baumeister, R. F. (2006). Alone but feeling no pain: Effects of social exclusion on physical pain tolerance and pain threshold, affective forecasting, and interpersonal empathy. Journal of Personality and Social Psychology, 91, 1-15. doi: 10.1037/0022-3514.91.1.1

Downs, V. C., \& Javidi, M. (1990). Linking communication motives to loneliness in the lives of older adults: An empirical test of interpersonal needs and gratifications. Journal of Applied Communication Research, 18, 32-48. doi: 10.1080/00909889009360313

Eisenberger, N. I., \& Lieberman, M. D. (2004). Why rejection hurts: A common neural alarm system for physical and social pain. Trends in Cognitive Sciences, 8, 294-300. doi: 10.1016/j.tics.2004.5.010

Eisenberger, N. I., Lieberman, M. D., \& Williams, K. D. (2003, October 10). Does rejection hurt? An fMRI study of social exclusion. Science, 302, 290-292. doi: 10.1126/science.1089134 
Floyd, K. (2002). Human affection exchange: V. Attributes of the highly affectionate. Communication Quarterly, 50, 135-154. doi: 10.1080/01463370209385653

Floyd, K. (2006a). Communicating affection: Interpersonal behavior and social context. Cambridge, England: Cambridge University Press.

Floyd, K. (2006b). Human affection exchange: XII. Affectionate communication is associated with diurnal variation in salivary free cortisol. Western Journal of Communication, 70, 47-63. doi: $10.1080 / 10570310500506649$

Floyd, K. (2014). Relational and health correlates of affection deprivation. Western Journal of Communication, 78, 383-403. doi: 10.1080/10570314.2014.927071

Floyd, K. (in press). Affection exchange theory. In C. R. Berger \& M. E. Roloff (Eds.), International encyclopedia of interpersonal communication. New York, NY: Wiley.

Floyd, K., Boren, J. P., Hannawa, A. F., Hesse, C., McEwan, B., \& Veksler, A. E. (2009). Kissing in marital and cohabiting relationships: Effects on blood lipids, stress, and relationship satisfaction. Western Journal of Communication, 73, 113-133. doi: 10.1080/10570310902856071

Floyd, K., \& Burgoon, J. K. (1999). Reacting to nonverbal expressions of liking: A test of interaction adaptation theory. Communication Monographs, 66, 219-239. doi: 10.1080/03637759909376475

Floyd, K., Hesse, C., \& Generous, M. A. (in press). Affection exchange theory: A bio-evolutionary look at affectionate communication. In D. O. Braithwaite \& P. Schrodt (Eds.), Engaging theories in interpersonal communication (2nd ed.). Thousand Oaks, CA: Sage.

Floyd, K., Hesse, C., \& Haynes, M. T. (2007). Human affection exchange: XV. Metabolic and cardiovascular correlates of trait expressed affection. Communication Quarterly, 55, 79-94. doi: $10.1080 / 01463370600998715$

Floyd, K., Mikkelson, A. C., Hesse, C., \& Pauley, P. M. (2007). Affectionate writing reduces total cholesterol: Two randomized, controlled trials. Human Communication Research, 33, 119-142. doi: 10.1111/j.1468-2958.2007.00293.x 
Floyd, K., Mikkelson, A. C., Tafoya, M. A., Farinelli, L., La Valley, A. G., Judd, J., et al. (2007a). Human affection exchange: XII. Affectionate communication accelerates neuroendocrine stress recovery. Health Communication, 22, 123-132. doi: 10.1080/1041023070145015

Floyd, K., Mikkelson, A. C., Tafoya, M. A., Farinelli, L., La Valley, A. G., Judd, J., et al. (2007b). Human affection exchange: XIV. Relational affection predicts resting heart rate and free cortisol secretion during acute stress. Behavioral Medicine, 32, 151-156. doi: 10.3200/BMED.32.4.151156

Floyd, K., \& Morman, M. T. (1997). Affectionate communication in nonromantic relationships: Influences of communicator, relational, and contextual factors. Western Journal of Communication, 61, 279-298. doi: 10.1080/10570319709374578

Floyd, K., \& Morman, M. T. (1998). The measurement of affectionate communication. Communication Quarterly, 46, 144-162. doi: 10/1080/01463379809370092

Floyd, K., \& Morman, M. T. (2000a). Affection received from fathers as a predictor of men’s affection with their own sons: Tests of the modeling and compensation hypotheses. Communication Monographs, 67, 347-361. doi: 10.1080/03637750009376516

Floyd, K., \& Morman, M. T. (2000b). Reacting to the verbal expression of affection in same-sex interaction. Southern Journal of Communication, 65, 278-299. doi: $10.1080 / 10417940009373177$

Floyd, K., Pauley, P. M., \& Hesse, C. (2010). State and trait affectionate communication buffer adults’ stress reactions. Communication Monographs, 77, 618-636. doi: 10.1080/03637751.2010.498792

Floyd, K., \& Riforgiate, S. (2008). Affectionate communication received from spouses predicts stress hormone levels in healthy adults. Communication Monographs, 75, 351-368. doi: $10.1080 / 03637750802512371$

Floyd, K., \& Voloudakis, M. (1999). Affectionate behavior in adult platonic friendships: Interpreting and evaluating expectancy violations. Human Communication Research, 25, 341-369. doi: 10.1111/j.1468-2958.1999.tb00449.x 
Floyd, N. S., Price, J. L., Ferry, A. T., Keay, K. A., \& Bandler, R. (2000). Orbitomedial prefrontal cortical projections to distinct longitudinal columns of the periaqueductal gray in the rat. Journal of Comparative Neurology, 422, 556-578. doi: 10.1002/1096-9861(20000710)422:4<556::AIDCNE6>3.0.CO;2-U

Grewen, K. M., Anderson, B. J., Girdler, S. S., \& Light, K. C. (2003). Warm partner contact is related to lower cardiovascular reactivity. Behavioral Medicine, 29, 123-130. doi:

$10.1080 / 08964280309596065$

Gupta, N. K., Mueller, W. H., Chan, W., \& Meininger, J. C. (2002). Is obesity associated with poor sleep quality in adolescents? American Journal of Human Biology, 14, 762-768. doi:

10.1002/ajhb.10093

Hansen, Å. M., Hogh, A., Persson, R., Karlson, B., Garde, A. H., \& Ørbæk, P. (2006). Bullying at work, health outcomes, and physiological stress response. Journal of Psychosomatic Research, 60, 6372. doi: 10.1016/j.jpsychores.2005.06.078

Hays, R. D., Sherbourne, C. D., \& Mazel, R. (1995). User's manual for the Medical Outcomes Study (MOS) core measures of health-related quality of life. Santa Monica, CA: RAND Corporation.

Herman, B. H., \& Panksepp, J. (1978). Effects of morphine and naloxone on separation distress and approach attachment: Evidence for opiate mediation of social affect. Pharmacology Biochemistry \& Behavior, 9, 213-220. doi: 10.1016/0091-3057(78)90167-3

Hesse, C., \& Floyd, K. (2008). Affectionate experience mediates the effects of alexithymia on mental health and interpersonal relationships. Journal of Social and Personal Relationships, 5, 793-810. doi: 10.1177/0265407508096696

Hitlan, R. T., Cliffton, R. J., \& DeSoto, M. C. (2006). Perceived exclusion in the workplace: The moderating effects of gender on work-related attitudes and psychological health. North American Journal of Psychology, 8(2), 217-236. 
Jaremka, L. M., Fagundes, C. P., Glaser, R., Bennett, J. M., Malarkey, W. B., \& Kiecolt-Glaser, J. K. (2013). Loneliness predicts pain, depression, and fatigue: Understanding the role of immune dysregulation. Psychoneuroendocrinology, 38, 1310-1317. doi: 10.1016/j.psyneuen.2012.11.016

Javaheri, S., Storfer-Isser, A., Rosen, C. L., \& Redline, S. (2008). Sleep quality and elevated blood pressure in adolescents. Pediatric Cardiology, 118, 1034-1040. doi:

10.1161/CIRCULATIONAHA.108.799410

Kimbrell, T. A., George, M. S., Parekh, P. I., Ketter, T. A., Podell, D. M., Danielson, A. L., ...Post, R. M. (1999). Regional brain activity during transient self-induced anxiety and anger in healthy adults. Biological Psychiatry, 46, 454-465. doi: 10.1016/S0006-3223(99)00103-1

King, A. C., Oman, R. F., Brassington, G. S., Bliwise, D. L., \& Haskell, W. L. (1997). Moderate-intensity exercise and self-rated quality of sleep in older adults: A randomized controlled trial. Journal of the American Medical Association, 277, 32-37. doi: 10.1001/jama.1997.03540250040029

Kross, E., Berman, M. G., Mischel, W., Smith, E. E., \& Wager, T. D. (2011). Social rejection shares somatosensory representations with physical pain. Proceedings of the National Academy of Sciences, 108, 6270-6275. doi: 10.1073/pnas.1102693108

Kurina, L. M., Knutson, K. L., Hawkley, L. C., Cacioppo, J. T., Lauderdale, D. S., \& Ober, C. (2011). Loneliness is associated with sleep fragmentation in a communal society. Sleep, 34, 1519-1526. doi: 10.5665/sleep.1390

Litzinger, S., \& Gordon, K. C. (2005). Exploring relationships among communication, sexual satisfaction, and marital satisfaction. Journal of Sex \& Marital Therapy, 31, 409-424. doi: $10.1080 / 00926230591006719$

MacDonald, G., \& Jensen-Campbell, L. A. (Eds.). (2011). Social pain: Neuropsychological and health implications of loss and exclusion. Washington, DC: American Psychological Association. doi: 10.1037/12351-000

MacDonald, G., \& Leary, M. R. (2005). Why does social exclusion hurt? The relationship between social and physical pain. Psychological Bulletin, 131, 202-223. doi: 10.1037/0033-2909.131.2.202 
Mahon, N. E. (1994). Loneliness and sleep during adolescence. Perceptual and Motor Skills, 78, 227-231. doi: 10.2466/pms.1994.78.1.227

Masten, C. L., Morelli, S. A., \& Eisenberger, N. I. (2011). An fMRI investigation of empathy for 'social pain' and subsequent prosocial behavior. NeuroImage, 55, 381-388. doi:

10.1016/j.neuroimage.2010.11.060

Menefee, L. A., Frank, E. D., Doghramji, K., Picarello, K., Park, J., Jalali, S., \& Perez-Schwartz, L. (2000). Self-reported sleep quality and quality of life for individuals with chronic pain conditions. Clinical Journal of Pain, 16, 290-297. doi: 10.1097/00002508-200012000-000003

Morman, M. T., \& Floyd, K. (1999). Affectionate communication between fathers and young adult sons: Individual- and relational-level correlates. Communication Studies, 50, 294-309. doi: $10.1080 / 10510979909388501$

Nelson, E. E., \& Panksepp, J. (1998). Brain substrates of infant-mother attachment: Contributions of opioids, oxytocin, and norepinephrine. Neuroscience \& Biobehavioral Reviews, 22, 437-352. doi: 10.1016/S0149-7634(97)00052-3

Niedhammer, I., David, S., Degioanni, S., Drummond, A., Philip, P., ... Vital, N. (2009). Workplace bullying and sleep disturbances: Findings from a large scale cross-sectional survey in the French working population. Sleep, 32(9), 1211-1219.

Oliver, J. M., Raftery, M., Reeb, A., \& Delaney, P. (1993). Perceptions of parent-offspring relationships as functions of depression in offspring: “Affectionless control," "negative bias,” and “depressive realism.” Journal of Social Behavior and Personality, 8(3), 405-424.

Owen, W. F. (1987). The verbal expression of love by women and men as a critical communication event in personal relationships. Women's Studies in Communication, 10(1) 15-24.

Panksepp, J. (2003, October). Feeling the pain of social loss. Science, 302, 237-239. doi: 10.1126/science.1091062

Panksepp, J., Herman, B. H., Conner, R., Bishop, P., \& Scott, J. P. (1978). The biology of social attachments: Opiates alleviate separation distress. Biological Psychiatry, 13(5), 607-618. 
Panksepp, J., Vilberg, T., Bean, N. J., Coy, D. H., \& Kastin, A. J. (1978). Reduction of distress vocalization in chicks by opiate-like peptides. Brain Research Bulletin, 3, 663-667. doi: 10.1016/0361-9230(78)90014-X

Paolacci, G., Chandler, J., \& Ipeirotis, P. G. (2010). Running experiments on Amazon Mechanical Turk. Judgment and Decision Making, 5(5), 411-419.

Patten, C. A., Choi, W. S., Gillin, J. C., \& Pierce, J. P. (2000). Depressive symptoms and cigarette smoking predict development and persistence of sleep problems in US adolescents. Pediatrics, 106, 1-9. doi: 10.1542/peds.106.2.e23

Pettit, J. D., Goris, J. R., \& Vaught, B. C. (1997). An examination of organizational communication as a moderator of the relationship between job performance and job satisfaction. International Journal of Business Communication, 34, 81-98. doi: 10.1177/002194369703400105

Peyron, R., Laurent, B., \& García-Larrea, L (2000). Appréciation par l’imagerie fonctionnelle des réponses cérébrales à la douleur: Revue et méta-analyse [Functional imaging of brain responses to pain: A review and meta-analysis]. Neurophysiologie Clinique, 30, 263-288. doi: 10.1016/S0987-7053(00)00227-6

Rotter, J. B., Chance, J. E., \& Phares, E. J. (1972). Applications of a social learning theory of personality. New York, NY: Holt, Rinehart \& Winston.

Schutz, W. (1958). FIRO: A three-dimensional theory of interpersonal behavior. New York, NY: Rinehart.

Schutz, W. (1966). The interpersonal underworld. Palo Alto, CA: Science and Behavior Books. Shrout, P. E., \& Bolger, N. (2002). Mediation in experimental and nonexperimental studies: New procedures and recommendations. Psychological Methods, 7, 422-445. doi: 10.1037/1082989X.7.4.422

Singleton, R. A., \& Wolfson, A. R. (2009). Alcohol consumption, sleep, and academic performance among college students. Journal of Studies on Alcohol and Drugs, 70(3), 355-363. 
Smart Richman, L., \& Leary, M. R. (2009). Reactions to discrimination, stigmatization, ostracism, and other forms of interpersonal rejection: A multimotive model. Psychological Review, 116, 365383. doi: $10.1037 / \mathrm{a} 0015250$

Steptoe, A., Owen, N., Kunz-Ebrecht, S. R., \& Brydon, L. (2004). Loneliness and neuroendocrine, cardiovascular, and inflammatory stress responses in middle-aged men and women. Psychoneuroendocrinology, 29, 593-611. doi: 10.1016/S0306-4530(03)00086-6

Steward, A. L., \& Lupfer, M. (1987). Touching as healing: The effect of touch on students’ perceptions and performance. Journal of Applied Social Psychology, 17, 800-809. doi: 10.1111/j.15591816.1987.tb00340.x

Spiegel, K., Leproult, R., \& Van Cauter, E. (1999). Impact of sleep debt on metabolic and endocrine function. Lancet, 354, 143-149. doi: 10.1016/S0140-6736(99)01376-8

Thomsen, D. K., Mehlsen, M. Y., Christensen, S., \& Zachariae, R. (2003). Rumination—relationship with negative mood and sleep quality. Personality and Individual Differences, 34, 1293-1301. doi: 10.1016/S0191-8869(02)00120-4

Thornhill, R., \& Thornhill, N. W. (1989). The evolution of psychological pain. In R. Bell (Ed.), Sociobiology and the social sciences (pp. 73-103). Lubbock: Texas Tech University Press.

Vangelisti, A. L., Pennebaker, J. W., Brody, N., \& Guinn, T. D. (2014). Reducing social pain: Sex differences in the impact of physical pain relievers. Personal Relationships, 21, 349-363. doi: 10.1111/pere.12036

Williams, K. D. (2007). Ostracism. Annual Review of Psychology, 58, 425-452. doi: 10.1146/annurev.psych.58.110405.085641

Wittmann, M., Dinich, J., Merrow, M., \& Roenneberg, T. (2006). Social jetlag: Misalignment of biological and social time. Chronobiology International, 23, 497-509. doi: $10.1080 / 07420520500545979$ 
Table 1

Multiple Regression Analysis for Physical Pain, Study One $(N=572)$

\begin{tabular}{llccccc}
\hline Step & Predictors & Zero-order $r$ & B & SE B & $\beta$ & $\Delta R^{2}$ \\
\hline & & & & & \\
& Age & $.12^{* *}$ & .02 & .01 & $.10^{*}$ & \\
& Sex & -- & .48 & .22 & $.09^{*}$ & \\
& Affection deprivation & $.14^{* *}$ & .16 & .05 & $.12^{* *}$ & $.014^{* *}$ \\
& & & & & & \\
\hline
\end{tabular}

Notes. $R^{2}=.037$; adjusted $R^{2}=.031 ; F(3,563)=7.13, p<.001 .{ }^{*} p<.05 ;{ }^{* *} p<.01$. Sex was dummy coded, so no zero order correlation was calculated. 
Table 2

Multiple Regression Analysis for Physical Pain, Study Two $(N=399)$

\begin{tabular}{|c|c|c|c|c|c|c|}
\hline Step & Predictors & Zero-order $r$ & B & SE B & $\beta$ & $\Delta R^{2}$ \\
\hline 1 & Age & $.17^{* *}$ & .04 & .01 & $.16^{* *}$ & \\
\hline & Sex & -- & .89 & .26 & $.17 * *$ & \\
\hline 2 & Affection deprivation & .03 & .19 & .06 & $.15^{* *}$ & $.023^{* *}$ \\
\hline
\end{tabular}

Notes. $R^{2}=.09$; adjusted $R^{2}=.08 ; F(3,389)=12.35, p<.001 .{ }^{*} p<.05 ; * * p<.01$. Sex was dummy coded, so no zero order correlation was calculated. 
Table 3

Multiple Regression Analysis for Sleep Quality, Study Two $(N=399)$

\begin{tabular}{llccccc}
\hline Step & Predictors & Zero-order $r$ & $\mathrm{~B}$ & $S E \mathrm{~B}$ & $\beta$ & $\Delta R^{2}$ \\
\hline 1 & Sex & -- & .95 & .33 & $.14^{* *}$ & \\
2 & Affection deprivation & $.27^{* *}$ & .47 & .08 & $.29^{* *}$ & $.084^{* *}$ \\
\hline
\end{tabular}

Notes. $R^{2}=.11$; adjusted $R^{2}=.10 ; F(2,392)=22.94, p<.001 .{ }^{*} p<.05 ;{ }^{* *} p<.01$. Sex was dummy coded, so no zero order correlation was calculated. 
Table 4

Correlations of Affection Deprivation and Individual Components of Disturbed Sleep

\section{Correlation with Affection Deprivation}

Sleep Disturbance Component

Study Two

Study Three

Sleep quality

$.23^{* *}$

$.27^{* *}$

Sleep latency

$.13^{*}$

$.22 * *$

Sleep duration

$.13^{* *}$

.10

Habitual sleep efficiency

$.16^{* *}$

.08

Sleep disturbance

$.24 * *$

$.20 * *$

Use of sleeping medication

.08

.05

Daytime dysfunction

$.22 * *$

$.29 * *$

Notes. All components are scored such that higher scores indicate poorer sleep quality. ${ }^{*} p<.05 ;{ }^{* *} p<$ .01 (two tailed). 
Table 5

Multiple Regression Analysis for Physical Pain, Study Three $(N=397)$

\begin{tabular}{llccccc}
\hline Step & Predictors & Zero-order $r$ & B & SE B & $\beta$ & $\Delta R^{2}$ \\
& & & & & \\
1 & Age & $.14^{* *}$ & .02 & .01 & .09 \\
& Sex & -- & .60 & .22 & $.15^{* *}$ & \\
& Affection deprivation & $.14^{* *}$ & .15 & .05 & $.15^{* *}$ & $.022^{* *}$ \\
& & & & & & \\
\hline
\end{tabular}

Notes. $R^{2}=.06$; adjusted $R^{2}=.06 ; F(3,388)=7.91, p<.001 .{ }^{*} p<.05 ;{ }^{* *} p<.01$. Sex was dummy coded, so no zero order correlation was calculated. 
Table 6

Multiple Regression Analysis for Sleep Quality, Study Three $(N=397)$

\begin{tabular}{lllllll}
\hline Step & Predictors & Zero-order $r$ & B & SE B & $\beta$ & $\Delta R^{2}$ \\
\hline & & & & & \\
& Age & $.11^{*}$ & .03 & .02 & .08 \\
& BMI & $.12^{*}$ & .08 & .03 & $.15^{* *}$ & \\
& Affection deprivation & $.27^{* *}$ & .46 & .09 & $.26^{* *}$ & $.07^{* *}$ \\
& & & & & & \\
\hline
\end{tabular}

Notes. $R^{2}=.10$; adjusted $R^{2}=.09 ; F(3,389)=14.02, p<.001 .{ }^{*} p<.05 ; * * p<.01$. BMI $=$ body mass index. 


\section{Endnotes}

${ }^{1}$ In each study, percentages for ethnic groups sum to $>100$ because participants could claim more than one ethnicity.

${ }^{2}$ In Floyd (2014), the scale items were worded to focus specifically on tactile affection; the modified scale used in the present studies focused on affectionate communication more generally.

${ }^{3}$ The CDC formula used to calculate BMI was: weight (lb) / [height (in) ${ }^{2}$ ] 703 